tion of the national and global asthma prevention programmes that have led to improved asthma management are thought to be involved in this change ${ }^{5}$; the impact of other (environmental) factors is more difficult to evaluate. A similar steadily decreasing trend was not found, however, in the percentage of men discharged during service as a result of asthma, which points to a need to re-examine selection and classification criteria for asthmatic men at call-up, as well as to better treatment during service.

Contributors: JL contributed to conception of the study and helped to acquire, analyse, and interpret the data and write the article. $\mathrm{LvH}$ helped to interpret data and drafted the article. HL helped to acquire the data and write the article. TH contributed to conception and design of the study and helped to interpret the data. JL is the guarantor(s) for the paper.

Funding: This research was funded partly by the Academy of Finland (project No 201346).
Competing interests: None declared.

Ethical approval: Not required. Access to armed forces databases was granted after a decision of the chief of the army staff (No 34/8/D/I/30.6.2003).

1 Braun-Fahrländer C, Gassner M, Grize L, Takken-Sahli K, Neu U, Stricker $\mathrm{T}$, et al. No further increase in asthma, hay fever and atopic sensitisation in adolescence living in Switzerland. Eur Respir J 2004;23:407-13.

2 Verlato G, Corsico A, Villani S, Cerveri I, Migliore E, Accordini S, et al. Is the prevalence of adult asthma and allergic rhinitis still increasing? Results of an Italian study.J J Allergy Clin Immunol 2003;111:1232-8.

3 Haahtela T, Lindholm H, Björksten F, Koskenvuo K, Laitinen LA. Prevalence of asthma in Finnish young men. BMJ 1990;301:266-8.

4 Bråbäck L, Hjern A, Rasmussen F. Trends in asthma, allergic rhinitis and eczema among Swedish conscripts from farming and non-farming environments. A nationwide study over three decades. Clin Exp Allergy 2004;34:38-43.

5 Haahtela T, Klaukka T, Koskela K, Erhola M, Laitinen LA. Asthma programme in Finland: a community problem needs community solutions. Thorax 2001;56:806-14.

(Accepted 31 March 2005)

doi 10.1136/bmj.38448.603924.AE

\title{
Changes in atopy over a quarter of a century, based on cross sectional data at three time periods
}

\author{
Malcolm Law, Joan K Morris, Nicholas Wald, Christina Luczynska, Peter Burney
}

Evidence that the prevalence of atopic diseases, including asthma and hay fever, has increased over the past 20-30 years comes mainly from questionnaire based surveys; objective measurements are limited. ${ }^{1-4}$ We therefore measured serological markers of atopic sensitisation in stored serum samples that had been collected from a population of men over about 25 years.

\section{Participants, methods, and results}

We used frozen $\left(-40^{\circ} \mathrm{C}\right)$ serum samples from men aged 40-64 years who had attended the British United Provident Association (BUPA) Medical Centre, London, for a routine medical examination. An advantage of this cohort is its socioeconomic homogeneity-almost all were professionals or businessmen. We matched (by age and month of attendance) the 513 samples from men who attended during 1996-8 to samples from 513 men seen in 1981-2 and 513 seen in 1975-6. The serum samples had not previously been thawed; previous work has shown negligible decay in IgE during storage of serum. ${ }^{5}$

\section{What is already known on this topic}

The prevalence of atopic diseases is increasing

Cross sectional studies show that the prevalence of atopy decreases with increasing age

\section{What this study adds}

Serological measurements at three time periods provide objective evidence that earlier birth cohorts were less likely to have become atopic than more recent ones; this accounts for the apparent decreasing prevalence of atopy with age
We first tested the samples using Phadiatop (Pharmacia \& Upjohn), a standard qualitative serological marker of atopy based on a mixture of 11 common, inhaled allergens (grass, tree, nettle, mugwort, mould, and olive; cat, dog, and horse dander; and two house dust mites). The positive samples were then tested for specific IgE to grass (timothy grass), tree mix (elder, silver birch, hazel, oak, and plane), and cat dander (Pharmacia CAP system); we did not test the Phadiatop negative samples because Phadiatop includes all these allergens. The samples were also tested for $\operatorname{IgG}$ antibody to hepatitis A (DiaSorin) and to Helicobacter pylori (samples from 1996-8 only; Axis-Shield Diagnostics).

The table shows that we found highly significant increases over time in the proportion of men positive to Phadiatop and with specific IgE to the three inhaled allergens. The average rate of increase was equivalent to an additional $4.5 \%$ of men becoming Phadiatop positive each decade.

We compared the data on men born in 1932-42 who had had serum taken in the earlier periods (1975-6 or 1981-2, at age 40-50) and on men born in the same years (1932-42) who had had serum taken in the later period (1996-8, at age 54-64). The proportions of samples positive to Phadiatop were similar for both the earlier and later periods $(35 \%$ and $34 \%$ respectively). The proportions of samples positive for specific IgE to grass, tree, and cat dander were also similar for the two time periods. In multiple regression, year of birth was associated with the prevalence of atopy $(\mathrm{P}<0.001)$, but current age was not.

This article was posted on bmi.com on 15 April 2005: http://bmj.com/cgi/doi/10.1136/bmj.38435.582975.AE
Centre for

Environmental and Preventive Medicine, Wolfson Institute of

Preventive

Medicine, Barts and

The London School of Medicine and Dentistry, London EC1M 6BQ

Malcolm Law professor

Joan K Morris

reader

Nicholas Wald professor

Department of Public Health Sciences, Division of Primary Care and

Public Health Sciences, Guy's, King's, and St Thomas' School of Medicine, Guy's Hospital, London SE1 3QD

Christina Luczynska honorary senior research fellow

Peter Burney professor

Correspondence to: Malcolm Law m.r.law@qmul.ac.uk BMJ 2005;330:1187-8 
Proportions of men aged 40-64 years positive to Phadiatop* and with specific IgE to three inhaled allergens, in three time periods, $\uparrow$ and mean annual increase in prevalence. Values are percentages (95\% confidence interval)

\begin{tabular}{lccccc} 
Year & Phadiatop & Grass & Tree & Cat \\
\hline $1975-6$ & $30(26$ to 34$)$ & $16(13$ to 19$)$ & $5.7(3.8$ to 8.0$)$ & 4.1 (2.6 to 6.2$)$ \\
\hline $1981-2$ & $33(29$ to 37$)$ & $18(14$ to 21$)$ & $5.1(3.3$ to 7.3$)$ & $4.5(2.9$ to 6.6$)$ \\
\hline $1996-8$ & $42(37$ to 46$)$ & $27(23$ to 31$)$ & $12.6(9.9$ to 15.8$)$ & 10.1 (7.6 to 13.1$)$ \\
\hline $\begin{array}{l}\text { Mean absolute } \\
\begin{array}{l}\text { annual increase in } \\
\text { prevalence }(\%) \ddagger\end{array}\end{array}$ & $0.45(0.17$ to 0.73$)$ & $0.53(0.30$ to 0.77$)$ & $0.36(0.19$ to 0.53$)$ & 0.25 (0.13 to 0.38$)$ \\
\hline
\end{tabular}

Test for trend $\left(\chi^{2}\right)$ was $\mathrm{P}<0.001$ for Phadiatop and for each of the three allergens.

*Preparation of 11 common, inhaled allergens used as a serological marker of atopy.

tIn each time period there were 513 age matched men.

†From logistic regression.

Our results do not support previous data suggesting an inverse association between two common enteric infections and adult atopy. The proportions of samples that were Phadiatop positive were similar in men with and without serological evidence of past hepatitis A infection (37\% $v$ 34\%) and Helicobacter pylori infection (40\% v 36\%). Two other markers of childhood infection available from questionnaire data-number of siblings and whether a man went to boarding school-also showed no association with Phadiatop positivity.

\section{Comment}

Our data show that atopy in middle aged men has increased during the last quarter of the 20th century and that the prevalence of atopy does not decline with increasing age; rather, more recent birth cohorts are more likely to have become atopic. Reports of increases over time in specific IgE to inhaled allergens in adults from Nordic countries and Swiss and Japanese schoolchildren ${ }^{1-4}$ involved younger subjects and shorter time periods than ours.

The reason for the increase in atopy is unknown. Our data suggest that it is unlikely to be an increased exposure to specific allergens (because sensitivity to both indoor and outdoor allergens increased). Our results also do not support the increase being due to declining childhood infections.

We thank the BUPA Foundation for support for maintaining the serum samples and database.

Contributors: ML conceived the study, JKM conducted the statistical analyses, CL did the serological measurements, and all authors contributed to the paper through shared discussion and data interpretation. ML and NW are the guarantors.

Funding: The Wellcome Foundation and the BUPA Foundation funded this study.

Competing interests: None declared.

Ethical approval: Not needed.

1 Nakagomi T, Itaya H, Tominaga T, Yamaaki M, Hisamatsu S-I, Nakagomi O. Is atopy increasing? Lancet 1994;343:121-2.

2 Linneberg A, Nielsen NH, Madsen F, Frølund L, Dirksen A, Jørgensen T. Increasing prevalence of specific IgE to aeroallergens in an adult population: two cross-sectional surveys 8 years apart: the Copenhagen allergy tion: two cross-sectional surveys 8 106:247-52.

3 Krause TG, Koch A, Firborg J, Poulsen LK, Kristensen B, Melbye M. Frequency of atopy in the Arctic in 1987 and 1998. Lancet 2002;360:691-2. quency of atopy in the Arctic in 1987 and 1998. Lancet 2002;360:691-2.
Kosunen TU, Höök-Nikannet J, Salomaa A, Sarna S, Aromaa A, Haahtela Kosunen TU, Höök-Nikannet J, Salomaa A, Sarna S, Aromaa A, Haahtela
T. Increase of allergen-specific immunoglobulin E antibodies from 1973 to 1994 in a Finnish population and a possible relationship to Helicobacter pylori infections. Clin Exp All 2002;32:373-8.

5 Potts J, Luczynska C, Chinn S, Jarvis D, Burney P. Comparison of IgE measurements using the Pharmacia CAP systems in the European community health surveys I and II. Eur Respir J 2002;20(suppl 38):120S.

(Accepted 16 March 2005)

doi 10.1136/bmj.38435.582975.AE
Medical Care Research Unit, School of Health and Related

Research, University of Sheffield,

Sheffield S1 4DA

Thomas E Locker research fellow in emergency medicine

Suzanne M Mason clinical senior lecturer in emergency medicine

Correspondence to: T Locker t.locker@ sheffield.ac.uk

BMJ 2005;330:1188-9
The NHS Plan stated: "By 2004 no one should be waiting more than four hours in Accident and Emergency from arrival to admission, transfer or discharge." ${ }^{1}$ This target was changed to allow for certain clinical exceptions, and since January 2005, 98\% of patients must spend less than four hours there. ${ }^{2}$ We analysed the distribution of time spent by patients in emergency departments in England.

\section{Participants, methods, and results}

We invited major emergency departments (those providing 24 hour cover and most core services) in England to submit data for each new patient attending during April 2004. We determined the distribution of total time in each department for patients who were admitted to hospital and for those discharged from the department. To assess the generalisability of these findings, we used performance data from the Department of Health to compare trusts in which at least one department had submitted data or in which no department had.

We received data from 83 departments detailing 428593 clinical episodes. Of these episodes, $72.8 \%$ $(\mathrm{n}=311957)$ resulted in discharge and 22.0\% $(\mathrm{n}=94200)$ in admission. Of the remaining episodes, $1 \%(\mathrm{n}=4452)$ were transferred, $0.2 \%(\mathrm{n}=975)$ died, and $3.9 \%(\mathrm{n}=16504)$ did not wait to be seen. In $0.1 \%$ $(n=505)$ of episodes the outcome was unknown. The figure shows the distribution of total time in the emergency department for episodes resulting in admission or discharge.

The median total time in the department for discharged patients was 96 minutes (98th centile $=341$ minutes); $91.0 \%(\mathrm{n}=283$ 894) of these patients spent $<220$ minutes in the department, with a further 3.6\% ( $\mathrm{n}=11$ 161) spending 220-239 minutes. We calculated separately for each department the mean age of

This article was posted on bmj.com on 20 April 2005:http://bmj.com/cgi/ doi/10.1136/bmj.38440.588449.AE 